\title{
Change in Proportion of Days Covered for Statins Following Implementation of a Pharmacy Student Adherence Outreach Program
}

\author{
Chloe Tamargo, PharmD, CPh; Karen Sando, PharmD, BC-ADM, BCACP; \\ Yesi Prados, PharmD, BCGP, CPh; and Kevin Cowart, PharmD, MPH, BCACP
}

\begin{abstract}
BACKGROUND: Nearly half of statin users discontinue therapy within the first year of treatment. Nonadherence to statin therapy may lead to an increased risk of atherosclerotic cardiovascular disease and, thus, higher costs due to hospitalizations. Value-based care models, such as accountable care organizations (ACO), are measured on adherence rates to statins through proportion of days covered (PDC). However, there is little research describing pharmacy student-based interventions within value-based care models.

OBJECTIVES: To (a) identify mean change in PDC for statins following implementation of a pharmacy student adherence outreach program and (b) identify the proportion of patients converted to $P D C \geq 0.80$ following the implementation of the outreach program.
\end{abstract}

METHODS: This single-center retrospective quasi-experimental study included patients actively enrolled in a Humana Medicare Advantage Prescription Drug (MA-PD) plan who completed at least 1 adherence outreach telephone call performed by a pharmacy student between January 1 , 2017, and December 31, 2017.

RESULTS: 99 patients met inclusion criteria. Atorvastatin was the most commonly prescribed statin (43\%), followed by simvastatin (38\%). Sixtyfour percent of patients had a baseline PDC of $<0.80$. Mean (SD) PDC was $0.66( \pm 0.24)$ before the pharmacy student adherence outreach intervention, and $0.79( \pm 0.23)-a 0.13$ increase-after the pharmacy student adherence outreach intervention $(P<0.001)$. Among patients who had $\mathrm{PDC}<0.80$ at baseline, $35 \%$ of patients $(n=35)$ were converted to $P D C \geq 0.80$ $(P<0.001)$, and $5 \%$ of patients with a baseline $P D C \geq 0.80$ had a decrease in PDC to $<0.80$ following the intervention.

CONCLUSIONS: Among patients enrolled in a Humana MA-PD plan within an ACO, mean PDC for statins increased following exposure to a pharmacy student adherence outreach program. One third of patients converted their PDCs to $\geq 0.80$ following the intervention. Value-based care programs may consider incorporating pharmacy student services to improve adherence to statins.

J Manag Care Spec Pharm. 2019;25(5):588-92

Copyright $\odot 2019$, Academy of Managed Care Pharmacy. All rights reserved.

\section{What is already known about this subject}

Medication nonadherence has been linked to higher costs of care and poor health outcomes.

Pharmacist interventions can improve medication adherence among patients with chronic conditions, although they may be costly to implement and sustain.

\section{What this study adds}

A pharmacy student adherence outreach program may improve medication adherence for statins among patients enrolled in a Humana Medicare Advantage Prescription Drug plan within an accountable care organization (ACO).

Pharmacy student-based clinical programs may have the potential to increase reimbursement and improve health care quality for an $\mathrm{ACO}$.

A ccording to the World Health Organization, "medication adherence" is defined as the degree to which a person's behavior corresponds with the agreed recommendations from a health care provider. ${ }^{1}$ Medication nonadherence is a growing concern to clinicians, health care systems, and health care payers involved in the care of patients with chronic conditions, given the association of medication nonadherence with adverse outcomes and higher costs of care. ${ }^{2}$

Recent clinical practice guidelines continue to emphasize the management of high blood cholesterol to reduce atherosclerotic cardiovascular disease (ASCVD) risk. ${ }^{3}$ HMG-CoA reductase inhibitors (statins) have extensive evidence for the greatest magnitude of ASCVD event reduction with the best margin of safety. ${ }^{4}$ However, adherence to therapies essential for cardiovascular disease risk reduction is low. ${ }^{5}$ Poor adherence is a major public health problem and may lead to substantial clinical and economic consequences. ${ }^{2,6}$ In a cohort study using claims data, full adherence to guideline-recommended medications (including statins) was associated with a lower rate of major adverse cardiac events and cost savings. ${ }^{7}$

In 2008, the Centers for Medicare \& Medicaid Services (CMS) implemented the Medicare Star Rating System to grade Medicare plan quality. ${ }^{8}$ However, since 2012, CMS has tied star ratings to plan revenue and other incentives. ${ }^{8}$ Medication adherence for the Medicare star ratings program uses a proportion of days covered (PDC) of $80 \%$ as the cutoff to define adherence. ${ }^{9}$ PDC is defined as the proportion of days in the measurement period "covered" by prescription claims for the same medication or another in its therapeutic category. ${ }^{10}$ Unlike certain quality measures that are under direct control of providers (e.g., prescribing medication at hospital discharge), medication adherence requires a partnership with patients to achieve therapeutic goals. 
Pharmacists are well suited to collaborate in a team-based practice model to improve medication adherence. ${ }^{11,12}$ However, the incorporation of a pharmacist into a team-based care model may be cost prohibitive to some institutions. ${ }^{12}$ Consequently, many institutions have explored the use of pharmacy technicians as pharmacist "extenders" to maintain or improve quality while attempting to decrease costs. ${ }^{13-16}$ The term "extenders" refers to the use of personnel who have the skill set to complete duties that can be overseen by a pharmacist. To our knowledge, the effect of using pharmacy students as pharmacist extenders to deliver medication adherence interventions for statins is unknown. Therefore, the primary objective of this study was to determine if the implementation of a pharmacy student medication adherence outreach program improved adherence to statins. The secondary objective was to determine the proportion of patients converted to $\mathrm{PDC} \geq 0.80$ following the pharmacy student medication adherence outreach program.

\section{Methods}

This was a single-center retrospective quasi-experimental study that included patients actively enrolled in a Humana Medicare Advantage Prescription Drug (MA-PD) plan and who also received primary care from a provider within an accountable care organization (ACO). Patients were required to have received at least 1 adherence outreach telephone call (intervention) from January 1, 2017, to December 31, 2017, performed by a pharmacy student in the Nova Southeastern University (NSU) College of Pharmacy Adherence Transitions and MTM (ATM) call center. This study was approved and classified as exempt by the NSU Institutional Review Board.

\section{Intervention}

In January 2017, the ATM call center created an adherence outreach program. At the time of completing this research, the program used only third- and fourth-year doctor of pharmacy students to conduct medication adherence telephone calls to patients in a Humana MA-PD plan within an ACO. There were no adherence outreach calls performed by a pharmacist during the intervention time period. Third-year pharmacy students were work-study students supervised by a pharmacist in the ATM call center. Fourth-year pharmacy students were completing a medication therapy management advanced pharmacy practice experience (APPE) and were also supervised by a pharmacist.

The intervention consisted of 3 phone calls conducted by a pharmacy student. Call recipients were randomly selected from a report of nonadherent patients based on $\mathrm{PDC}<0.85$. Reports were received quarterly from the ACO corporate office and contained all patients who were taking medications in the following classes: angiotensin-converting enzyme inhibitors, angiotensin II receptor blockers, oral antidiabetic agents, and statins. The report included patient name; date of birth; PDC; the name, location, and phone number of the pharmacy of last fill; last fill date; days supply; last date on hand; and prescriber information. PDC was calculated according to measure specifications by the Pharmacy Quality Alliance. ${ }^{10}$ Patients were required to have filled at least 2 prescriptions for a statin or statin combination on 2 unique dates of service in the measurement period.

The initial adherence outreach call consisted of a questionnaire that used the Drug Adherence Work-up (DRAW) tool to help identify any barriers to medication adherence. ${ }^{17}$ Additionally, the pharmacy student confirmed the diagnosis for each medication, medication name, and dosage with the patient and followed the DRAW patient interview questions, using suggested actions and guides. Using DRAW, students helped guide the patient to develop a plan to address any medication nonadherence barriers that were identified. Follow-up calls were conducted within 1 week from the initial call to reinforce any concerns from the initial call. Reminder calls were conducted 10 days before the patient's next fill date. Study data obtained from telephonic communication and chart review were collected and managed using REDCap electronic data capture tools hosted at Nova Southeastern University.

Pharmacy students underwent motivational interviewing (MI) training conducted by the director of the ATM call center before conducting the intervention. Pharmacy students also received electronic health care documentation and workflow training in the ATM call center. The MI, electronic health care documentation, and workflow training consisted of webinars and demonstration videos. Practice telephone calls were performed with the director of the ATM call center. General and individual feedback was given to pharmacy students before and throughout the intervention period.

\section{Inclusion Criteria}

Patients were screened for inclusion into the adherence outreach program during the study time frame if they were aged 18 years or older, were English or Spanish speaking, had a $\mathrm{PDC}<0.85$, were actively enrolled in the Humana MA-PD plan, and completed at least 1 adherence outreach telephone call during the study period with a pharmacy student.

\section{Exclusion Criteria}

Patients were excluded from the adherence outreach program if they were institutionalized (assisted-living facility, skilled nursing facility, or nursing home) at the time of the initial adherence outreach call, and if the patient had no final PDC reported following the intervention (due to discontinuation of the medication, change of physicians, or death).

\section{Outcome Measures}

The primary objective of this study was to determine if the implementation of a pharmacy student medication adherence 
outreach program improved adherence to statins. To determine if an improvement in medication adherence occurred, the mean change in PDC for statins was calculated by subtracting the first PDC reported after the patient received at least 1 pharmacy student adherence phone call (postintervention) from the PDC reported immediately preceding the first adherence phone call (baseline or pre-intervention). The secondary objective was to identify the proportion of patients with a baseline $\mathrm{PDC}<0.80$ who were converted to a $\mathrm{PDC} \geq 0.80$ following the intervention.

\section{Statistical Analysis}

The primary and secondary outcomes were analyzed using inferential and descriptive statistics. Mean change in PDC was compared using a paired sample t-test. The proportion of patients converted to $P D C \geq 0.80$ was compared with the McNemar test. Data were analyzed using SPSS version 24 (IBM, Armonk, NY) with all $P$ values less than 0.05 considered to be statistically significant.

\section{Results}

A total of 99 patients met inclusion criteria. Baseline characteristics are described in Table 1. Atorvastatin was the most commonly prescribed statin (43\%), followed by simvastatin (38\%). Approximately $64 \%$ of patients had a baseline PDC of $<0.80$ before the intervention.

As shown in Table 2, mean PDC increased following the pharmacy student adherence outreach program (0.13 increase; $P<0.001)$. Among patients who had a $\mathrm{PDC}<0.80$ at baseline, $35 \%$ of patients were converted to a PDC $\geq 0.80(P<0.001)$, and $5 \%$ of patients who had a PDC $\geq 0.80$ at baseline had a decrease in PDC to $<0.80$ following the intervention. Overall, $26 \%$ of patient PDCs decreased $(n=24)$ or did not change $(n=2)$ following the intervention.

\section{Discussion}

The adherence outreach program described in this study aimed to improve patients' understanding of the purpose of their medications, directions for use, how to monitor for adverse effects, the identification of barriers to adherence, and ways to overcome potential barriers to adherence to reach a PDC of $\geq 0.80$. In addition to demonstrating feasibility and utility of involving pharmacy students in a medication adherence outreach program, we observed statistically significant findings with just over a third of patients in this study having their PDCs converted to $\geq 0.80$, and only $5 \%$ had their PDCs decrease to $<0.80$ during the study time frame.

This study demonstrated that a pharmacy student adherence outreach program may have the potential to improve medication adherence for statins among patients enrolled in a MA-PD plan within an ACO. More than 32 million Medicare patients receive prescription drug benefits through Medicare Part D. ${ }^{18}$ Improving medication adherence among these patients may

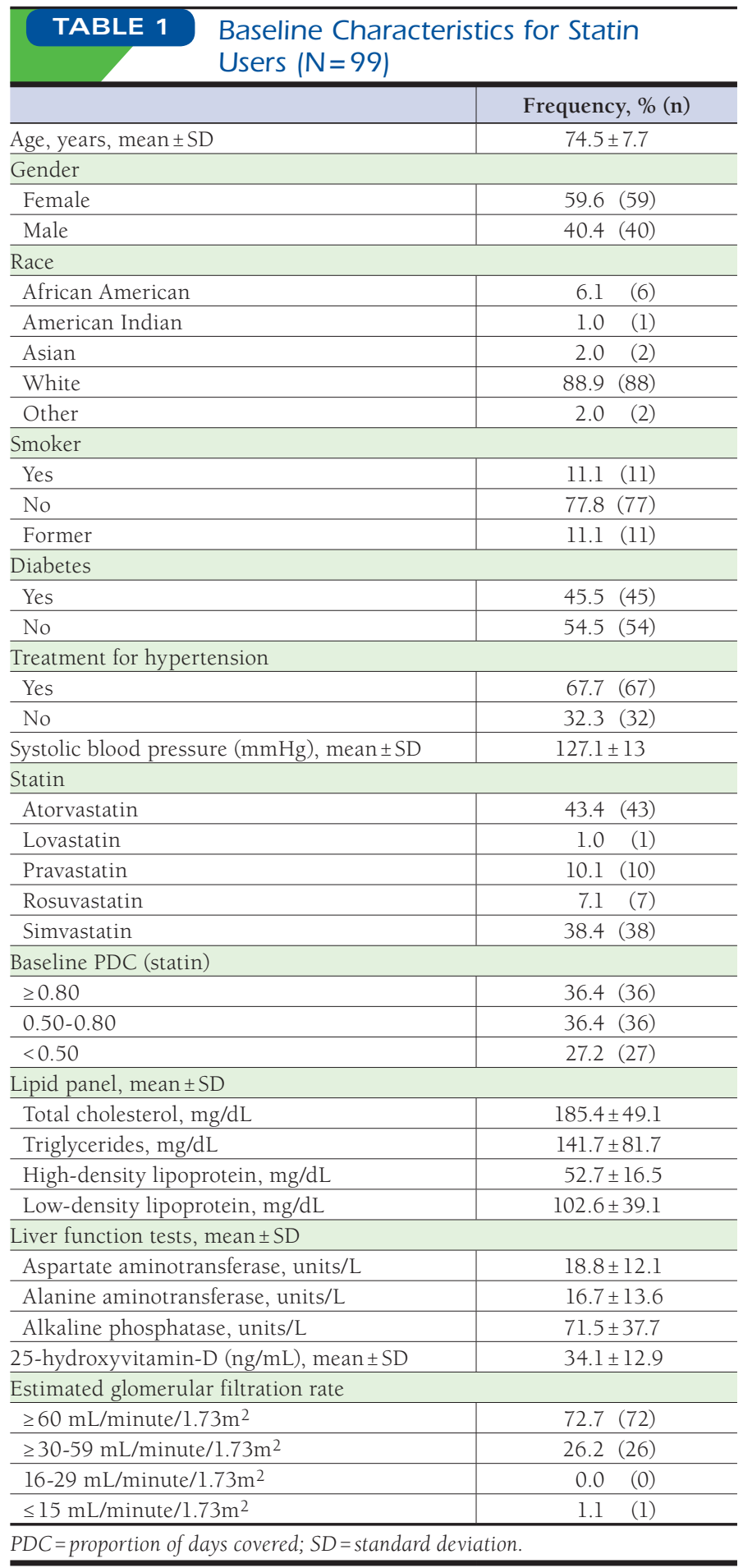

enhance CMS star measures, resulting in financial bonuses and improved health outcomes. ${ }^{19}$ To our knowledge this is the first study to report findings of a pharmacy student adherence outreach program within a value-based care setting. 


\begin{tabular}{cc|c}
\hline TABLE 2 & $\begin{array}{l}\text { Mean Change in PDC for Statin } \\
\text { Users in an MA-PD Plan Receiving } \\
\text { Pharmacy Student Adherence Outreach } \\
\text { Intervention }(\mathrm{N}=99)\end{array}$ \\
\hline $\begin{array}{c}\text { PDC Before } \\
\text { Intervention } \\
\text { Mean } \pm \text { SD) }\end{array}$ & $\begin{array}{c}\text { PDC After } \\
\text { Intervention } \\
\text { (Mean } \pm \text { SD) }\end{array}$ & P Value \\
\hline $0.66 \pm 0.24$ & $0.79 \pm 0.23$ & $<0.001$ \\
\hline
\end{tabular}

aP value was compared using a paired sample t-test.

$M A-P D=$ Medicare Advantage Prescription Drug plan; $P D C=$ proportion of days covered; $S D=$ standard deviation.

In an observational analysis conducted in an internal medicine clinic, a pharmacy student program designed to monitor direct oral anticoagulants demonstrated that the most common intervention was related to medication adherence. ${ }^{20}$ Therefore, future research may consider expanding clinical services involving pharmacy students to other high-risk medication classes that suffer from low adherence rates. Given that we only investigated statins in this study as a pilot project, future studies investigating adherence to other medications included in the CMS star measures (renin-angiotensin system antagonists or oral antidiabetic agents) are needed.

Accreditation standards for pharmacy education mandate that pharmacy students should be competent in providing patient-centered and population-based care. ${ }^{21}$ Colleges and schools of pharmacy are required to place students in practice settings where authentic patient care interactions will prepare them for practice; however, colleges and schools of pharmacy often struggle to quantify the effect that students have on patient care outcomes. One school's documentation system analyzed student-based clinical interventions over a 3-year period and identified a variety of interventions that students contributed to that had improved clinical and economic outcomes, including medication dosage adjustments, patient and provider education, and identification of drug-related problems. ${ }^{22}$ In the current study, we demonstrated that pharmacy students during didactic training and those completing an APPE may contribute to improved medication adherence measures. ACOs may consider use of pharmacy students to perform a variety of medication-related services that may affect quality measures and reimbursement.

\section{Limitations}

This study has several limitations that should be discussed. PDC is the recommended methodology by the Pharmacy Quality Alliance and CMS for estimation of medication adherence for patients using chronic medications. ${ }^{23}$ While an ideal PDC has not been established, a PDC of at least 0.80 is considered acceptable in many chronic disease states. PDC is a newer, more conservative measure of refill record-based adherence and, despite variations in PDC calculations,${ }^{24}$ tends to provide a more operational measure of adherence than medication possession ratio.

During the study time frame, the ATM call center worked closely with an affiliated ACO, which also used pharmacists embedded into primary care physician offices. Therefore, we were unable to distinguish which patients (if any) had an additional intervention with any of the embedded pharmacists in those primary care clinics. An intervention with a clinic-based pharmacist may have contributed to changes in PDC beyond calls placed by the pharmacy student as part of the outreach program.

Since this is an observational study, a direct cause and effect relationship with respect to the exposure and outcome could not be established. At the time of data collection for study, the ATM call center was newly established, and the researchers lacked historical data to use as a comparison cohort. Additionally, we did not have access to member enrollment data during the study time frame, and patients in the study may have experienced different lengths of exposure to the intervention, which was not captured. Future studies should consider capturing this data to adjust for variation in the exposure and potential confounders.

Finally, this study only reported adherence to statins, which was performed as a pilot project. As such, data for angiotensinconverting enzyme inhibitors, angiotensin II receptor blockers, and oral antidiabetic agents were not analyzed during this research.

Although these limitations may affect internal validity of the findings, the results describe the successful integration of pharmacy students as pharmacist extenders within a valuebased care environment. Interventions that use pharmacy students, which aim to contain costs and maximize quality in value-based care settings, should be explored in future research.

\section{Conclusions}

Among patients enrolled in a Humana MA-PD plan within an ACO, mean PDC for statins significantly increased following exposure to a pharmacy student adherence outreach program. A third of patients had their PDCs converted to $\geq 0.80$ following the intervention. Value-based care programs may consider creating pharmacy student-based interventions to improve quality and decrease costs. Pharmacy students may be a valuable cost-saving resource and can be used with an adherence outreach program to provide patient education, reminder tools, and emphasize proper medication administration. 


\section{Authors}

CHLOE TAMARGO, PharmD, CPh; KAREN SANDO, PharmD, BC-ADM, BCACP; YESI PRADOS, PharmD, BCGP, CPh; and KEVIN COWART, PharmD, MPH, BCACP, Nova Southeastern University College of Pharmacy, Davie, Florida.

AUTHOR CORRESPONDENCE: Kevin Cowart, PharmD, MPH, BCACP, Assistant Professor, University of South Florida College of Pharmacy, 12901 Bruce B Downs Blvd., MDC 30, Tampa, FL 33612. Tel.: 813.974.4568; E-mail: kcowart1@health.usf.edu.

\section{DISCLOSURES}

No outside funding supported this research. The authors have no financial conflicts of interest to disclose. At the time of conducting this research, all authors were employed at Nova Southeastern University.

Preliminary results were presented as a poster at the AMCP Managed Care \& Specialty Pharmacy Annual Meeting; April 23-26, 2018; Boston, MA.

\section{REFERENCES}

1. Sabaté E, ed. Adherence to long-term therapies: evidence for action. World Health Organization. 2003. Available at: http://www.who.int/chp/ knowledge/publications/adherence_report/en/. Accessed March 3, 2019.

2. Osterberg L, Blaschke T. Adherence to medication. N Engl J Med. 2005;353(5):487-97.

3. Grundy SM, Stone NJ, Bailey AL, et al. 2018 AHA/ACC/AACVPR/AAPA/ ABC/ACPM/ADA/AGS/APhA/ASPC/NLA/PCNA guideline on the management of blood cholesterol: a report of the American College of Cardiology/ American Heart Association Task Force on Clinical Practice Guidelines. J Am Coll Cardiol. In press.

4. Stone NJ, Robinson JG, Lichtenstein AH, et al. 2013 ACC/AHA guideline on the treatment of blood cholesterol to reduce atherosclerotic cardiovascular risk in adults: a report of the American College of Cardiology/ American Heart Association Task Force on Practice Guidelines. Circulation. 2014;129(25 Suppl 2):S1-S45.

5. Naderi SH, Bestwick JP, Wald DS. Adherence to drugs that prevent cardiovascular disease: meta-analysis on 376,162 patients. Am J Med. 2012;125(9):882-87.

6. Desai NR, Choudhry NK. Impediments to adherence to post myocardial infarction medications. Curr Cardiol Rep. 2013;15(1):322.

7. Bansilal S, Castellano JM, Garrido E, et al. Assessing the impact of medication adherence on long-term cardiovascular outcomes. J Am Coll Cardiol. 2016;68(8):789-801.

8. Grzeskowiak D, Zenner P. Medicare Advantage star ratings: basics and best practices. Milliman white paper. November 2017. Available at: http:// www.milliman.com/uploadedFiles/insight/2017/medicare-advantage-starratings-best-practices.pdf. Accessed March 3, 2019.
9. Centers for Medicare \& Medicaid Services. Quality measures. December 2, 2017. Available at: https://www.cms.gov/Medicare/Quality-InitiativesPatient-Assessment-Instruments/QualityMeasures/index.html. Accessed March 3, 2019.

10. Pharmacy Quality Alliance. PQA measure overview. Available at: https:// www.pqaalliance.org/assets/Measures/PQA Measure Overview 082018.pdf. Accessed March 3, 2019.

11. Lee JK, Grace KA, Taylor AJ. Effect of a pharmacy care program on medication adherence and persistence, blood pressure, and low-density lipoprotein cholesterol: a randomized controlled trial. JAMA. 2006;296(21):2563-71.

12. Skelton JB, Binaso KA. DOTx.MED: pharmacist-delivered interventions to improve care for patients with diabetes. J Am Pharm Assoc. 2012;52(1):25-37.

13. Bailey JE, Surbhi S, Bell PC, Jones AM, Rashed S, Ugwueke MO. SafeMed: using pharmacy technicians in a novel role as community health workers to improve transitions of care. J Am Pharm Assoc. 2016;56(1):73-81.

14. Bush PW, Daniels R. Health care systems and transitions of care: implication on interdisciplinary pharmacy services. N C Med J. 2017;78(3):177-80.

15. Gernant SA. Optimizing the role of pharmacy technicians in patient care settings: nationally recognized, standardized training for technicians in pharmacist-delivered cognitive services. J Am Pharm Assoc. 2018;58(1):9-11.

16. Irwin AN, Ham Y, Gerrity TM. Expanded roles for pharmacy technicians in the medication reconciliation process: a qualitative review. Hosp Pharm. 2017;52(1):44-53.

17. Doucette WR, Farris KB, Youland KM, Newland BA, Egerton SJ, Barnes JM. Development of the Drug Adherence Work-up (DRAW) tool. J Am Pharm Assoc. 2012;52(6):e199-204.

18. Rucker NL. Medicare Part D's medication therapy management: shifting from neutral to drive. AARP Public Policy Institute. Insight on the Issues, no. 64. June 2012. Available at: https://www.aarp.org/content/dam/aarp/ research/public_policy_institute/health/medicare-part-d-shifting-from-neutral-to-drive-insight-AARP-ppi-health.pdf. Accessed March 3, 2019.

19. Centers for Medicare \& Medicaid Services. Trends in Part C \& D star rating measure cut points. Available at: https://www.cms.gov/Medicare/ Prescription-Drug-Coverage/PrescriptionDrugCovGenIn/Downloads/2014Trends-in-Part-C-and-D-Star-Rating-Measure-Cut-Points.pdf. Accessed March 15, 2019

20. Kim JJ, Hill HL, Groce JB 3rd, Granfortuna JM, Makhlouf TK. Pharmacy student monitoring of direct oral anticoagulants. J Pharm Pract. 2018;31(5):462-68.

21. Accreditation Council for Pharmacy Education. Accreditation standards and key elements for the professional program in parmacy leading to the doctor of pharmacy degree. February 2, 2016. Avalable at: https://www. acpe-accredit.org/pdf/Standards2016FINAL.pdf. Accessed March 3, 2019.

22. Divall MV, Zikaras B, Copeland D, Gonyeau M. School-wide clinical intervention system to document pharmacy students' impact on patient care. Am J Pharm Ed. 2010;74(1):14.

23. Pharmacy Quality Alliance. PQA measure use in CMS' Part D quality programs. Available at: https://www.pqaalliance.org/medicare-part-d. Accessed March 15, 2019.

24. Choudhry NK, Shrank WH, Levin RL, et al. Measuring concurrent adherence to multiple related medications. Am J Manag Care. 2009;15(7):457-64. 